\title{
Commercial Success by looking for Desire Lines
}

\author{
Carl Myhill \\ User Experience Group, GE Network Reliability Products and Services, Energy Services, \\ Elizabeth House, 1 High Street, Chesterton, Cambridge, UK \\ carl.myhill@litsl.com http://www.litsl.com
}

\begin{abstract}
Desire Lines' are the ultimate unbiased expression of natural human purpose and refer to tracks worn across grassy spaces, where people naturally walk - regardless of formal pathways. This perfect expression of natural purpose can extend into other interactions in the real world and in the software world.

Rather than trying to understand user needs from a focus group, being alert for desire lines will show you users' actual purpose more directly. Smart companies have an obsession with what is typed into their Search facility, analysing hourly this pure expression of what people want from their sites.

'Normanian Natural Selection' is proposed to describe survival of the fittest design. Companies focusing on desire lines apparent in their products, will be able to successfully adapt them to what their users really want. Perhaps these positive adaptions in design, aligned with human natural purpose, will lead to their greater commercial success.
\end{abstract}

\section{Desire Lines}

The term 'Desire Line' originates from the field of urban planning and has been around for almost a hundred years [1]. A desire line normally refers to a worn path showing where people naturally walk. Desire lines are an ultimate expression of human desire or natural purpose. An optimal way to design pathways in accordance with natural human behaviour, is to not design them at all. Simply plant grass seed and let the erosion inform you about where the paths need to be. Stories abound of university campuses being constructed without any pathways to them. Planners responsible earn great respect for their cunning in allowing the desire lines to form before finalizing the construction of the paved pathways. Reconstruction of paths across Central Park in New York was famously based on this approach [2].

Desire lines are such a perfect expression, or rather impression, of human natural purpose that they are the ultimate design pattern for building pathways [3]. Looking at such desire lines as shown in figure 1, it is easy to imagine people, like a line of ants, marching along the route to their goal. In this case, ignoring the formal path off to the left and instead marching over the fence, across the car park and directly towards the entrance to the store. 


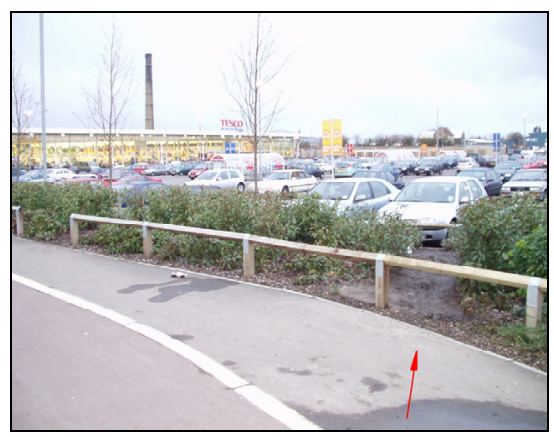

Fig. 1. Photo of desire line towards the entrance to a Cambridge Supermarket built in 2003

\section{Extending The Concept of Desire Lines}

Desire lines normally refer to pathways across open spaces but they are such perfect impressions of things that humans actually try to do (rather than what they say they are trying to do), that perhaps the concept can be extended. How else can we see the snail trails left by human natural purpose? Can such trails help us design better? To explore these questions, I took a trip into town.

\subsection{Speed Humps - 200m}

$200 \mathrm{~m}$ into my trip I came upon speed humps, a traffic calming measure designed to slow down motorists. As I watched cars proceed over the humps, like watching a line of ants, I could see a very definite behavior pattern. In figure 2 you can see that the car in the foreground appears parked. In fact, this vehicle is traveling at speed and has swerved into the curbside because the speed humps dip at the edges. The natural desire of certain drivers to maintain their speed over the speed humps leads them to take the path of least resistance, or least bump, to their progress.

Is there a desire line here? The tarmac prevents there being a desire line left carved in the road for all to see. The curbstones display considerable scratching from over zealous speedsters and the wheels of cars getting this slightly wrong will be tell tale. However, in this case, watching the cars, as if a line of ants, is perhaps the clearest approach to seeking the natural human behavior in this situation. A more relevant expression of the consequences of this human or driver desire to maintain speed would be accident statistics. You can clearly see in figure 2 that cars performing this maneuver cut into the curbside so dramatically that any cyclist there would be crushed. It is likely that accident statistics will be blamed on driver error, or cyclists, rather than on the design of the traffic calming measures which cause the problem but these statistics are perhaps the most relevant expression of the consequences of human behavior here. 


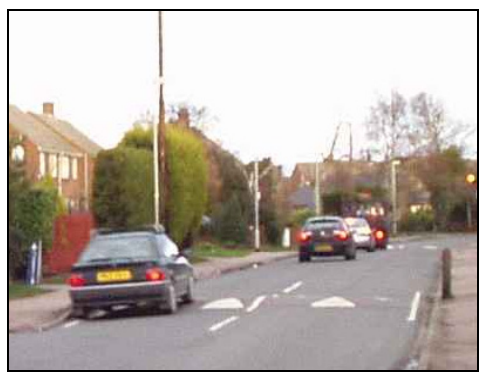

Fig. 2. Photo of speeding traffic crossing a speed hump, swerving curbside to minimize bump.

\subsection{Combined Use Pedestrian and Cycle Bridge $-500 \mathrm{~m}$}

As I cross the bridge on my bike I can't help noticing the behavior of the ants in their natural purpose. The bridge shown in figure 3 has an exit arrangement with a clear design intent - cyclists to the left; pedestrians to the right (cows to remain on the common, hence the grid). What do the ants do? On the whole, the majority of ants, whether on foot or on a bicycle will traverse the grid. The gate, designed for pedestrians is rarely opened in the natural scheme of things.

Inconsequential or ephemeral desire lines might be broken heels from shoes or angry exchanges between cyclists and pedestrians. The grid perhaps shows indications that it is traversed by other than just cycle tyres but again, in this case, the strongest impression of natural human purpose is gained from observing the ants.

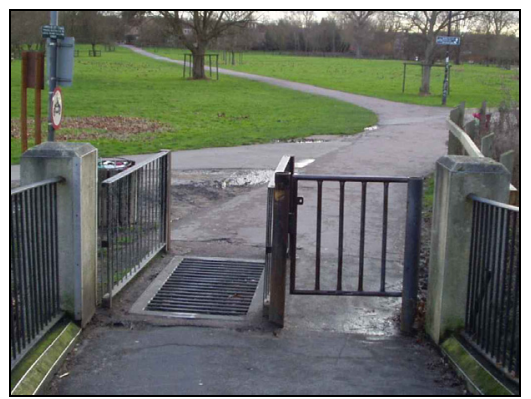

Fig. 3. Photo of an exit to a combined use bridge, which way do the pedestrians go?

\subsection{Rising Bollards $-\mathbf{2 0 0 0 m}$}

On to my favorite desire line in town, the rising bollards. The idea behind these traffic measures is to only allow access into the Cambridge's inner ring road to authorized vehicles, such as taxis and buses and delivery vans. Ever increasing numbers of signs tell the unsuspecting tourist not to proceed, some of which can be seen in figure 4 . 


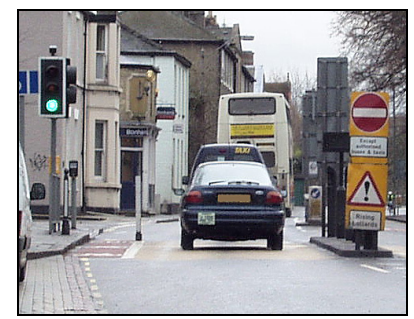

Fig. 4. Authorized vehicles proceeding over rising bollards.

The desire lines are very easy to see and although recorded as accident statistics, there is no doubt what is to blame for standing in the way of natural human purpose on this occasion. The unsuspecting tourist driving into central Cambridge, on a road that was open to the public only a few years ago, is now baffled with signs. Never mind the signs, the car in front is going this way so it must be ok.

The natural human desire of driving into central Cambridge conspires with befuddling sign posts to lead the unsuspecting 'unauthorized' vehicles over the rising bollards. The bollards will appear sunken if the unsuspecting driver is following an ordinary looking authorized vehicle. It is hard to believe that what happens next to the unsuspecting driver is the complete destruction of their car from the bollard punching upwards as they progress over it. The desire line impression of this context reinforces our understanding of the problem - there is a regular appearance of destroyed cars at the side of the road, and newspaper headlines such as, "Two in hospital after rising bollards hit cars" [6]

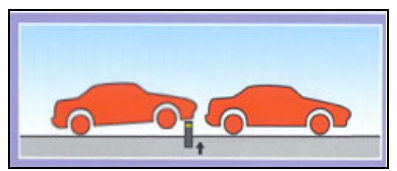

Fig. 5. An unauthorized vehicle is destroyed as it follows an authorized vehicle through the rising bollard. Adapted from [5].

The attitude of those responsible for the bollards is to blame drivers and deny the desire line clearly showing that there is a problem here, "Sue Hewitt, who manages the bollards for Cambridgeshire County Council, admitted she was concerned at the number of accidents at the spot, but insisted drivers were to blame."[6]

The severity of the penalty for people getting this wrong is tremendous but there is no denying the fact that human purpose or desire continues to lead unsuspecting motorists onwards to their destruction. No matter what signposts indicate, people don't expect to be punished for a motoring error by having a huge iron pole punch its way through the bottom of their car!

However much the officials blame the motorists, the desire line tells the actual story of the human behavior in this context. 


\subsection{Speed Cameras and Speed Warning Signs - 6000m (north or south)}

If you head north out of Cambridge you'll soon come upon speed cameras. These cameras will photograph your car registration number plate if you are driving too fast and send you a fine and traffic endorsement through the post (sometimes this can lead to a complete ban).

There is always debate about the intentions of such cameras - do they really want to slow down traffic or just raise funds? Either way, the desire lines are very clear. On sight of a speed camera, people driving speeding cars perceive a THREAT and brake HARD. Desire lines appear in the form of rubber tire tracks on the road, and accident statistics are argued to back up claims that the cameras cause accidents [7]. Natural human behavior in this context is to brake hard.

A design refinement recently introduced was to paint the cameras yellow, so drivers have an earlier warning and can start their excessive braking earlier.
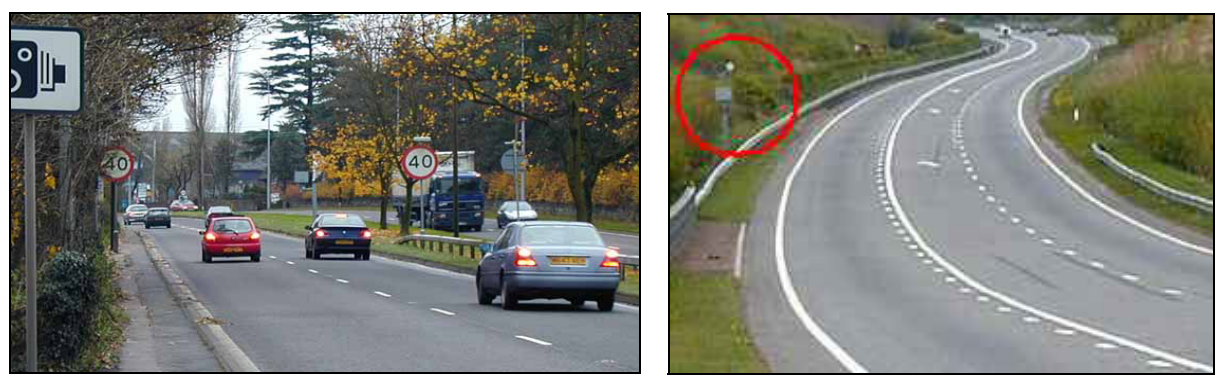

Fig. 6. Cars under heavy braking on noticing speed camera; and skid marks on road next to speed camera

Heading south out of Cambridge, through the village of Hauxton a different kind of approach to slowing traffic has been installed. These are non-threatening speed warning signs which check the speed of the approaching vehicle and only illuminate if the speed limit is being exceeded.

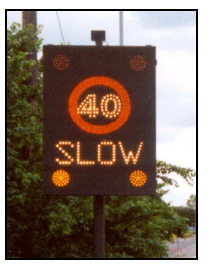

Fig.7. Speed triggered, but unthreatening, speed warning sign

There are no real desire lines relating to the speed warning sign but observing the line of drivers as they pass through this zone is striking. With the polite and nonthreatening reminder of the speed limit, the motorists naturally slow down, without sudden braking. 


\subsection{Back Home - Cook tops}

Back home I am reminded of desire lines in my household products, for example, those relating to cook tops (or hobs). A survey of 400 cook tops [4] found that many available for sale in the UK in 2003 suffered from a poor mapping of controls to elements. This is a well understood design flaw - in 1959 Chapanis and Lindenbaum [8] found hob design layouts yielding errors up to 11\% and in 1979 Ray and Ray [9] replicated the results finding errors up to 19\%. Even though we've known about this problem for 45 years, the majority of new cook tops designed replicate the bad design.

Does this kind of bad design have a desire line? Perhaps the most obvious desire line would be to look at household fire statistics. A 1997 report by the UK government [10] found cooking to be the second highest cause of household fire. Of these, cookers left unattended represented $75 \%$ of the incidents. I wonder for what proportion of those people turned on the wrong burner by mistake?

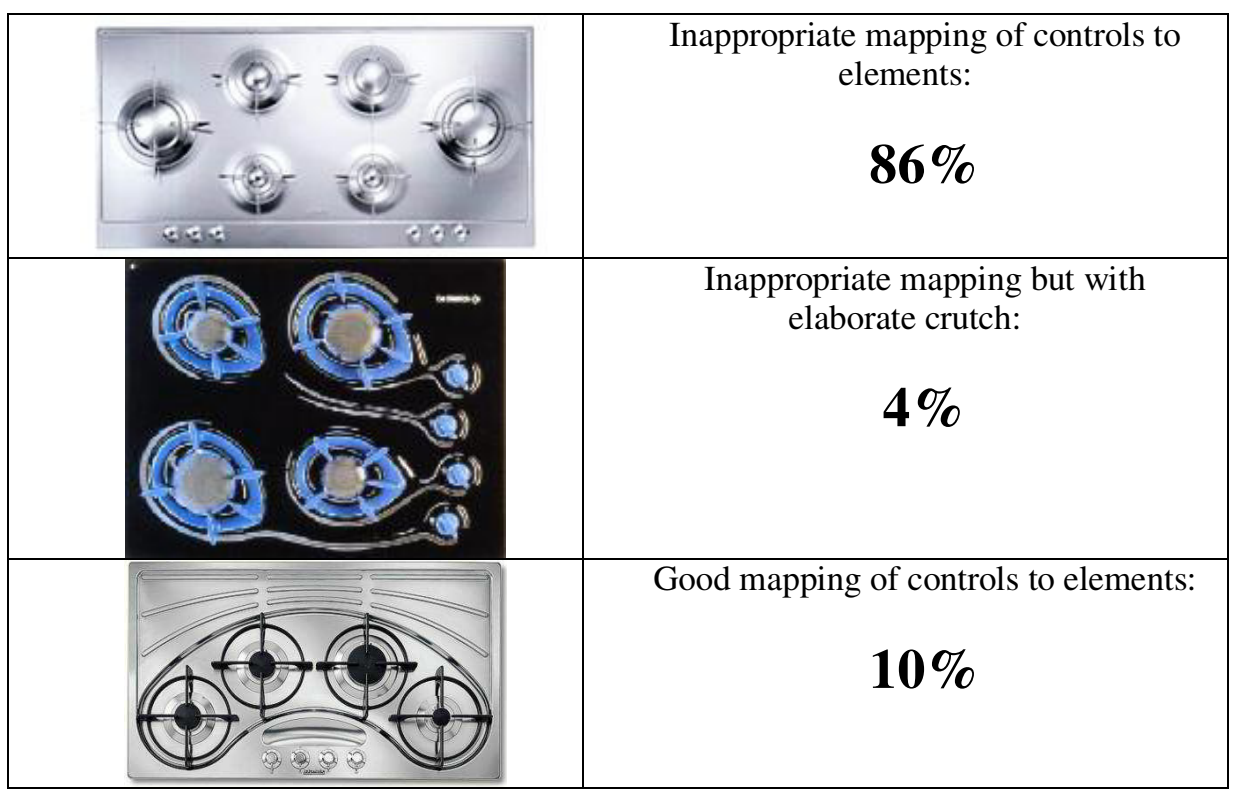

Fig. 8. Kinds of cook tops available in the UK in 2003 from [4]

We know there is a design problem here. We know that cookers are a primary cause of household fire. This would seem to be a desire line worth investigating, though as you might expect the government report made no mention of the design of cook tops.

\subsection{Desire Lines on Aircraft - Visa Waiver I-94 Form}

Extending the concept of desire lines to the real world would not be complete without mentioning the US Visa Waiver form. As aircraft begin their approach into a US 
destination, flight crews hand out Visa Waiver I-94 forms, warning you not to make a mistake because this can delay you getting through immigration.

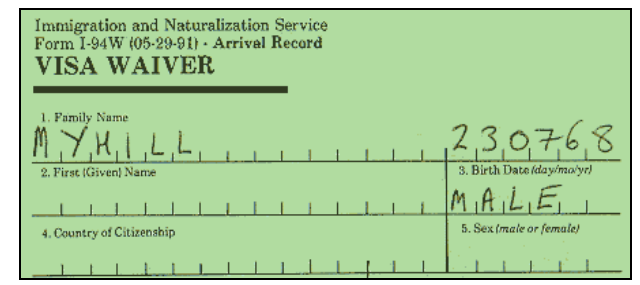

Fig. 9. Spot the desire line across a US Immigration I-94 form

Figure 9. shows the common error - the date of birth is on the wrong line. How often are these forms filled out incorrectly in a way which is clearly obvious from the desire line left on the form itself? Such statistics are not available but it seems a safe bet that the desire lines are ignored. A simple design adaption of this form could fix the problem and could fractionally speed up US immigration procedures. However, this is perhaps not a desire line which is has much commercial significance.

Form design is clearly an area where desire lines have relevance. Researchers know the importance of running pilot studies of forms and questionnaires and very often look for common mistakes, or omissions in how people filled out the pilot questionnaires - they actively seek the desire lines.

Perhaps the most famous case of poor form usability in recent times can be seen from the 'butterfly ballot' desire lines [11]. Mistakes made on the ballot paper created desire lines which probably changed an election result in Florida in 2000!

\section{Relating Desire Lines to Computers}

Slightly broadening the concept of desire lines from muddy tracks across grass, it is possible to see other impressions of human desire or purpose in the field of computing, many of which could be heeded for commercial advantage.

\subsection{Keyboard and Mouse Arrangement}

It's not too hard to see the workstation arrangement shown in figure 9 as something analogous to a muddy track across a park. Natural human desire to interact with a computer for the purpose of employment or enjoyment can lead to consequences which are far more undesirable than a muddy track. This is actually my workstation. Repetitive Strain Injury (RSI) has led me to learn how to use the mouse left-handed; the split keyboard forces my hands into a more natural position for typing and the wrist restraint keeps my wrist at a good angle preventing further damage. Whilst not providing any answers, the desire line from this interaction is very clear. 


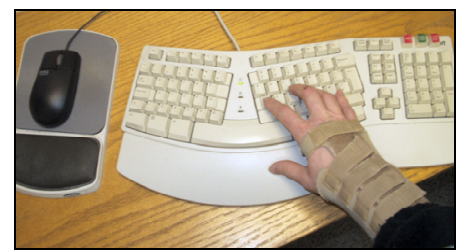

Fig. 10. Desire line computer interface - keyboard and mouse of a computer user with RSI

\subsection{Website Security Questions}

When my bank asked me for security information for accessing my on-line account, one piece of information was a memorable date. This date was to be typed into a free format text field. It turned out that the security question was a bit harder to remember than just a date - you had to remember the precise string format you used to enter that date. Given the breadth of string formats for entering a valid date, it seems likely that a desire line would form in the bank's logs of security failures.

For illustration, suppose the date were 23/7/1968. Login failures would include the following and many more: 23/07/1968; 23/7/68; 23/07/68; 23 July 1968; 23 July 68; 23rd July 1968.

Some analysis of security check failures in this case would very likely show many people had the correct date, which was the intended security information, but the incorrect string syntax. Attention to this desire line could have quickly improved usability of user access to this on-line bank account.

In this case though, there was another desire line which the bank did observe. I emailed them to explain the problem to them and they fixed it. Actively listening and genuinely acting on user feedback is akin to planting grass seed on a new university campus and watching where the pathways form. This is well recognized good business sense but few companies successful handle these gems of information.

\subsection{Software Support Organisations}

I recently bought a cup of coffee during a long car journey and after 20 minutes the bottom of the cup started to leak. Interestingly, this company, 'Coffee Nation' had the idea of putting 'Express Yourself' labelling on their cups, asking for feedback. I'm not sure why a company which has vending machines in petrol stations would really be quite so geared up for feedback but in their approach, they are observant for the desire lines.

Too often, support organizations in software companies do the opposite of this they do a great job of hiding desire lines. Smart support folks solve problems and tell users how to get around problems. They are often not put in a position to influence design, and may not realize a design problem even exists - just more problems with stupid users.

Support organizations, if not attuned to seeking and acting on desire lines, very often spend their entire existence covering them up. The same problem occurs with many customer services teams whose immediate priorities seem to be getting the 
complaining customer off the phone, rather than deriving any insight from what they are saying. Customer services departments offer routine disinterest in customer feedback. Hiding desire lines in this way is becoming an increasingly risky business in the commercial world. Companies like Coffee Nation already have a competitive advantage from their attention to their product's desire lines.

\subsection{Products Which Ask for Feedback - Apple iTunes \& Microsoft Windows}

There is evidence that some companies are attuned to desire lines. Apple have a menu item on iTunes labeled, 'Provide iTunes Feedback'. Actively seeking direct feedback from users in the actual moment they are using the software is a great way of watching a desire line form. There have to be benefits from observing closely the precise desires of your users at the point where they are being true to their natural desires rather than abstracted out of this context in an interview or focus group. Combined with Apple's reputation for design, and the cult status of their products and wildly loyal customers, it is easy to see that their attention to desire lines will continue to pay off.

Microsoft have a similar idea, when a Windows program crashes a dialog box appears asking you to "send an error report". Somehow I feel uncomfortable about such snooping on my computer but the intention of looking for the effects of actual use of their products, in critical situations like system crashes, has to be a positive move, which will ultimately improve their product design.

\subsection{Website Statistics and Search}

The beauty of desire lines comes from the fact that their impressions express pure human purpose. Website statistics of various kinds can show you what users are actually doing with your website. Perhaps the most powerful of these is the free format text people type into web search boxes, which creates desire lines showing what people are trying to find on your site. Very smart companies make a great deal of such information, for example the BBC [12],[13] check these desire lines hourly. They adapt other aspects of their web user interface and information structure, such as their subject index, based on what people are typing into the Search facility.

Hill, Holland et al [14] introduced the idea of modeling 'wear' from the physical world (like the bindings of paperbacks) to the digital world to indicate frequency of use of digital objects. They were initially concerned with 'edit wear' and 'read wear' and modeling the frequency with which parts of a document had been read or written. Perhaps the analysis of search terms on a website is a similar concept - 'search term wear'. An example from the BBCi search facility demonstrates this. When Eastenders (a UK soap opera) was removed from the main BBCi index page, it quickly became the top search term typed into the BBCi search facility - this heavy search term wear drove a re-think of Eastenders place in the index!

Overall, website statistics and in particular those relating to search (or search term wear), show a true impression of what a user wants from your website, not what they say they want but what they actually want and what they do. Companies ignoring this information are ignoring their customers at their peril. 


\subsection{Rate This Page / Was This Review Helpful?}

Microsoft and others routinely offer the opportunity to rate a page of information from their online knowledge-base. Did the article help solve your problem? There are desire lines here, though at times I wonder whether this is effectively analyzed, so rarely can I answer in the affirmative.

A more effective rating system is perhaps that adopted by Amazon. Desire lines are captured for the benefit of other users by allowing readers to declare whether they found a particular review helpful or not.

This is another example of actively seeking desire lines in the context of use, also close to the concept of 'read wear' - Amazon clearly lead the way here and seems to be aware that this kind of thing is what keeps them ahead of their competition.

\subsection{On-line Help}

Online Help facilities within applications often seem to not help much. They typically have no means of allowing the desire line of natural purpose to leave an impression. If you don't find what you want in the help, that information is lost.

Perhaps it is time for designers to invest some time in ensuring that Help systems actually do help by analysing desire lines, particularly what it is users are typing into search boxes. Combine that with a 'rate this page' system and Help systems could evolve.

\subsection{Automated Teller Machines (ATMs)}

Desire lines surrounding certain ATMs are great fun. There is a standard interaction sequence for ATMs, the user is given their card back before they get the cash (there is even a delay before the cash comes out to allow the user to put their card safely away!). The standard design pattern for this sequence is presumably because when people have their desire satisfied, i.e. getting the cash, they perceive task closure. It is therefore perplexing to discover a lack of adherence to this design pattern in certain ATMs in the USA, which distribute the cash before returning the card. A desire line you might expect in this instance would be a high incidence of lost cards. Such commercial loses would, you would hope, lead to focus on the design of the ATMs but perhaps not always.

\section{Normanian Natural Selection}

Don Norman has given us many examples of how humans naturally interact with everyday things as well as computers (e.g. The Psychology of Everyday Things [15]). Extending the urban planning concept of 'desire lines' allows us to look at the tracks left by these natural human interactions in everyday life, and in computing. Somewhat casually drawing further parallels with nature, is it possible to consider that a kind of natural selection is evident in the evolution of design? Capitalist economies arguably have parallels with nature, and in particular, can contribute to the commercial 
favoring of one design over another. Could the concept of Normanian Natural Selection [4] gain ground, describe commercial design evolution where only slightly successful adaptations are needed for a design to begin to prosper but where unfavorable adaptations die out?

Given 2 identical websites for example, one with the desire line from the search facility analyzed daily and the other ignored, would the former evolve more successfully and ultimately win out in the commercial Normanian Natural Selection stakes? This question seems ridiculous, though it describes the current commercial context of the web very adequately.

\section{Concluding Remarks}

Expressions of human purpose or desire are all around us, not just available as muddy tracks across open spaces. The urban planning concept of desire lines provides such a perfect expression of human desired purpose that it seems like a worthy concept to explore elsewhere.

We've seen that in some cases, observing humans interacting in the real world provides such a clear indication of their natural purpose that no desire line is needed. Instead, watching the people is much like watching marching ants navigating an obstacle. Speeding vehicles approaching a speed camera provide an excellent example of these marching ants with their obstacle.

Taking a short trip into town I've come across a variety of desire lines all around us that could be used to inform design of anything from speed humps, to rising bollards.

In software terms, the desire lines concept matches very closely to aspects of web interfaces like search boxes, where users type in exactly what they want, as they think it should be expressed. Such information is gold dust to companies looking for competitive advantage.

It is not news that successful companies listen closely to their customers. It is however quite surprising that more companies do not actively seek to understand what drives their users, when there are desire lines left all over the place should they choose to look for them.

Companies like Apple, survive and carve ever deeper market niches. Apple users are not just customers - they are wildly loyal. Apple know about the principle which underlies the extended concept of desire lines. They don't refer to a concept of Normanian Natural Selection perhaps, but they understand design evolution.

Even when the consequences of natural human purpose, are very severe, there is no denying a desire line - it shows what people actually do in some etched form or another.

Normanian natural selection of design will have the last word in the raw commercial world, as Darwinian natural selection does in nature. Successful adaptions lead to commercial superiority and survival, failing to adapt will allow designs to lose ground and die out. Desire lines showing natural human purpose relating to a design are not so hard to see, yet few companies focus on them. Notably, successful companies do focus on them to stay ahead, like Apple, Microsoft and Amazon. Usually, market forces lead commercial competition and erode advantage of very successful companies on the very things they do well. Perhaps the lack of 
evidence for this is an indication that many companies still do not perceive clearly enough the commercial value of usability. Turning to look for some desire lines could be a good place to start - it is certainly a memorable concept!

\section{References}

1. Throgmorton, James A, Eckstein, Barbara: Desire Lines: The Chicago Area Transportation Study and the Paradox of Self in Post-War America. Published on-line (http://www.nottingham.ac.uk/3cities/throgeck.htm) with selected proceedings of the 3Cities Conference. Birmingham, England (2000).

2. Barlow Rogers, Elizabeth: Rebuilding Central Park: A Management and Restoration Plan. The MIT Press (1987)

3. Christopher Alexander, Murray Silverstein, Shlomo Angel, Sara Ishikawa, and Denny Abrams: The Oregon Experiment. Oxford University Press (1975.) ISBN 0-19-501824-9

4. Myhill, Carl: Get your product used in anger!: (before assuming you understand its requirements). Interactions, volume 10, issue 3 May \& June 2003. ACM Press, New York, NY, USA (2003) (12-17)

5. Calderdale Council Website: (http://www.calderdale.gov.uk/roadstransport/highways/improvements4/loading.html) (2004)

6. Cambridge Evening News: Available in online news archive (http://www.cambridgenews.co.uk/archives/2001/08/09/lead5.html ) (09/08/2001)

7. Speed camera plan 'may cause deaths'. BBC News: Available online (http://news.bbc.co.uk/1/hi/health/1976907.stm). (9/5/2002)

8. Chapanis, A. and Lindenbaum, L.E.: A reaction time study of four control-display linkages. Human Factors 1(4): 1-7. (1959)

9. Ray, R. D., and Ray, W. D.: An Analysis of Domestic Cooker Control Design. Ergonomics, 22(11), 1243- 1248. (1979).

10 Reynolds, Cath: Causes of fire deaths. Research Report No.72. ISBN 185893778 7. Office of the Deputy Prime Minister. (1997)

11 The US 2000 Election and Voting Issues. Usability Professionals' Associaton. Available online http://www.upassoc.org/upa_projects/voting_and_usability/2000election.html. (2000)

12.Belam, Martin: Usability Aspects of BBCi Search Engine. UK UPA meeting, London (15th April 2003)

13.Belam, Martin: A Day In The Life Of $\mathrm{BBCi}$ Search. Online http://www.currybet.net/articles/day_in_the_life/index.shtml

14.Hill, W.C., Hollan, J. D., Wrobelwski, D. and McCandless, T.: Read wear and edit wear. In Proceedings of ACM Conference on Human Factors in Computing Systems, CHI '92: 3-9. (1992)

15.Norman, Don: The Psychology of Everyday Things. Basic Books, Inc, New York (1988) 